MSCRA

4,1

2

Received 3 May 2021

Revised 22 July 2021

13 November 2021

2 December 2021

Accepted 8 December 2021

\section{Resilience in the supply chain management: understanding critical aspects and how digital technologies can contribute to Brazilian companies in the COVID-19 context}

\author{
Vitor William Batista Martins \\ State University of Pará, Belém, Brazil and \\ University of Campinas, Campinas, Brazil \\ Rosley Anholon \\ University of Campinas, Campinas, Brazil \\ Walter Leal Filho \\ Hamburg University of Applied Sciences, Hamburg, Germany, and \\ Osvaldo Luiz Gonçalves Quelhas \\ Federal Fluminense University, Niterói, Brazil
}

\begin{abstract}
Purpose - The present study aims to identify the most critical elements of resilience in the management of supply chains of Brazilian companies and, in the sequence, debate possible digital technologies mentioned by literature to enhance them.

Design/methodology/approach - To identify the most critical elements, the information provided by qualified academics was used. Data analysis was performed through Cronbach's alpha coefficient, hierarchical cluster analysis and Fuzzy TOPSIS approach.

Findings - Comparatively, the results pointed out three elements of resilience as the most critical in managing supply chains. They are the decision-making (understood as the definitions from the layout of the chain's operations network to the choice of warehouse locations, distribution centres and manufacturing facilities), human resources (understood as management for human resources development and knowledge management through training) and security (understood as issues related to information technology for data security). For each of them, bibliographic research was performed to identify technologies that enhance these elements of supply chain management resilience.

Originality/value - The results presented here can significantly contribute to the expansion of debates associated with resilience in managing supply chains of Brazilian companies and directing researchers in the area.
\end{abstract}

Keywords Resilience, Supply chain management, COVID-19 pandemic, Digital technologies, Brazil Paper type Research paper

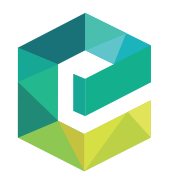

(C) Vitor William Batista Martins, Rosley Anholon, Walter Leal Filho and Osvaldo Luiz Gonçalves Quelhas. Published in Modern Supply Chain Research and Applications. Published by Emerald Publishing Limited. This article is published under the Creative Commons Attribution (CC BY 4.0) licence. Anyone may reproduce, distribute, translate and create derivative works of this article (for both commercial and non-commercial purposes), subject to full attribution to the original publication and authors. The full terms of this licence may be seen at http://creativecommons.org/licences/by/4.0/ legalcode

Funding: This research was funded by Conselho Nacional de Desenvolvimento Científico e Tecnológico-CNPq-Brazil, grant number 307536/2018-1 and 305442/2018-0. Universidade do Estado do Pará-UEPA — Brazil, grant number 626/18.
Modern Supply Chain Research and Applications
Vol. 4 No. 1,2022 pp. $2-18$ Emerald Publishing Limited 2631-3871 DOI 10.1108/MSCRA-05-2021-0005 


\section{Introduction}

In recent years, efficiency in supply chain management (SCM) has been an intensely debated topic in the academic and industrial environment. Much of this interest is due to globalisation, which increasingly requires that companies integrate their entire supply chain, aiming to enhance the use of resources, develop skills and ensure business continuity. This search has brought together researchers, professors and managers to ensure constant improvements, involving agents that work throughout the entire production network (Aloini et al., 2015; Ballou, 2004; Cao et al., 2010; Dwivedi et al., 2020; Modak et al., 2020).

Scholten and Schilder (2015) characterise resilience as the ability of the entire supply chain to react to abrupt interruptions. In the same line of reasoning, Hosseini et al. (2019) argue that resilience is evidenced when the production network can support, adapt and recover to meet customer demand and ensure planned performance.

Digital technologies present an essential role for companies to become more resilient since, broadly, they directly impact strategic decisions and, consequently, the level of resilience (Hosseini and Ivanov, 2019; Karmaker and Ahmed, 2020; Yadav et al., 2020). Samson (2020) promotes considerable agility in SCM, impacting product designs, production and distribution. A specific example that may be cited here is the use of blockchain. According to Dutta et al. (2020), the use of blockchain technology enhances supply chain resilience by reducing the impacts of unexpected interruptions through a preventive and proactive approach to risk management, thereby providing more excellent protection for the entire network that makes up the chain, the importance of risk management is corroborated by Walker-Munro (2021). The benefits provided by digital technologies are potentialised when companies combine them with efficient recruitment and training of human resources (Elibal and Ozceylan, 2021; Hosseini and Ivanov, 2019; Samson, 2020).

Focusing on the impacts of the COVID-19 pandemic in supply chains, Sharma et al. (2020) argue that they were observed in practically all network companies' links in all sectors. Manufacturers, retailers and wholesalers worldwide have been forced to adapt their business. These authors argue that the models and structures adopted by most companies need to be critically analysed by managers to adapt and increase their robustness. The first step towards a better understanding of supply chains' resilience level is characterised by a critical analysis of them in light of the current concepts mentioned (Sharma et al., 2020).

Focusing Brazilian scenario, it is essential to remember that most Brazilian companies were severely affected by the Covid-19 pandemic. In many companies, important management factors previously neglected were evidenced. Concepts related to resilience can be cited as an example. The importance of resilience for companies in the pandemic period is reinforced by Jabbour et al. (2020). In addition, the Brazilian public debt has increased due to public spending to combat the pandemic and economic problems will be noted in the next years (Anholon et al., 2021). Therefore, analysing critical elements of resilience in the Brazilian scenario and possible ways to enhance the enterprises' robustness can be understood as a research gap.

Based on the context presented above, this article aims to identify the most critical elements of resilience in the management of supply chains in Brazilian companies and, in the sequence, debate possible digital technologies mentioned by literature to enhance them. Regarding identifying the most critical elements of resilience, it is essential to highlight that this research does not focus on specific cases, but it aims to understand, comparatively, the most critical resilience elements in Brazilian reality in a general way.

\section{Theoretical background}

The concept of SCM can be understood as the management of product flow across all links in a production chain, from the supplier to the end customer; for that, initiatives aimed at
Resilience in the supply chain

management

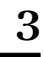


MSCRA

4,1

4

continuous improvement and that integrate all the agents involved (Green et al., 2019; Theagaraja and Manohar, 2015; Tortorella et al., 2017). In the same line of reasoning, Singh et al. (2017) argue that the concept above is associated with an organisational structure that makes it possible to integrate buyers and sellers focusing on adding value. For Sharma and Modgil (2019), the search for excellence in SCM becomes a significant competitive advantage for companies directly or indirectly related to the processes of a production network.

The search for competitive advantage in SCM is based on the concept of resilience. This concept has been explored by academic research for decades (Adobor, 2019; Alfarsi et al., 2019) and that is gaining attention with instabilities and uncertainties generated by the COVID-19 pandemic (Chowdhury et al., 2020). For Tukamuhabwa et al. (2015), resilience in $\mathrm{SCM}$ is characterised by the adoption of initiatives that allow a quick return of operations after interruption suffered, and this concept is corroborated by Cheng and $\mathrm{Lu}$ (2017), Alfarsi et al. (2019) and Ali et al. (2021).

Sawyerr and Harrison (2020) highlight the most cited elements of resilience in SCM in the academic literature, namely, "Collaboration; Flexibility; Redundancy; Agility; Decision making; Security (IT and insurance); Culture; Robustness; Integration; Avoidance; Human Resource Management; Sustainability and Logistics capability" (Sawyerr and Harrison, 2020). These authors emphasise the importance of understanding each element to achieve a resilient supply chain model. Table 1 presents the definition of these concepts. Authors that corroborate with the definitions mentioned are also presented. Also presented are the terminologies through which the elements will be referenced in the analysis of results.

Regarding the COVID-19 pandemic, Yaya et al. (2020) point out that it created an environment of uncertainty due to the restrictions imposed on global trade and the flow of people. Consequently, it exposed weaknesses in many companies' supply chains, thus showing ample improvement possibilities (Paul and Chowdhury, 2021). Queiroz et al. (2020) corroborate previous statements, arguing that pandemics can cause significant damage to supply chains in different sectors. For these authors, analyses related to the network's adaptation, digitisation, preparation, recovery, whip effect and sustainability can make it more robust about the mentioned damages.

According to Cai and Luo (2020), the assessment of the impacts of COVID-19 on the supply chain is characterised as the first step towards the definition of countermeasures to be taken. The authors cite as an example the automotive supply chain, in which the interruption in the supply of raw materials and spare parts and other inconveniences have intensified during the pandemic; the solution for them is related to the resilience concepts.

Other interesting examples that address the concept of supply chain resilience in the context of the COVID-19 pandemic were cited by Yu et al. (2020) and Singh et al. (2021). Yu et al. (2020) analysed the pharmaceutical supply chain. They pointed out five critical points to be improved in it, namely, decision-making under uncertainty, planning considering agility, resilience and sustainability, analysis of interest conflicts among agents in global value chains, sustainability assessment of the life cycle of pharmaceutical product systems and, finally, development of medicines allocation strategies under resources and/or supply constraints.

Focusing on the impact of the pandemic in food sector chains, several studies can be mentioned. Singh et al. (2021) analysed the impact on the mentioned sector via simulations, aiming to understand how their resilience is affected; these simulations can be used as a basis for decision-making quicker and more assertive. Coopmans et al. (2021) developed a study in which they analysed the impact of the pandemic on the agri-food sector; they identified that the sanitary crisis caused a change in demand and, consequently, a significant disturbance in the processes of production, processing and marketing of food in terms of organisation, planning, operation, logistics and economic return on work. Additionally, Love et al. (2021) highlight that the pandemic has considerably compromised the food chain's safety and 


\section{Element}

Definition

Collaboration (E 01)

Flexibility (E 02)

Redundancy (E 03)

Agility (E 04)

Decision-making

(E 05)

Security (E 06)

Culture (E 07)

Robustness (E 08)

Integration (E 09)

Prevention (E 10)

Human resources

(E 11)

Sustainability (E 12)

Logistics capacity

(E 13) corroborated by Tukamuhabwa et al. (2015)

Note(s): Based on Sawyerr and Harrison (2020); authors that corroborate some of the elements are presented in the Table
Collaboration is understood as the integration of elements and the mutual availability of resources among agents in the supply chain to optimise chain management as a whole

Flexibility throughout the chain is understood as the availability of various transport options, products, processes, order fulfilment and even contracts with suppliers

Redundancy is understood as the existence of alternative plans in terms of capacity, employees, facilities and even the number of suppliers

Agility is understood as the ability of the chain to respond and adapt to meet unforeseen demands

Decision-making is defined as the layout of the chain's operations network to the choice of warehouse locations, distribution centres and manufacturing facilities Security is understood as the issue related to information technology for data security. This is corroborated by Ivanov (2020)

Culture is understood as the way learning is created throughout the chain and the sharing and recording of information and risk forecasting

Robustness is understood as the capacity that the supply chain has to transform, learn and innovate

Integration is understood as to how supply chain agents and suppliers guarantee competitive advantage. This is corroborated by Ali et al. (2021)

Prevention is understood as the ability to predict the risks inherent in the operation of the supply chain. This is corroborated by Ali et al. (2021)

This element is understood as management for human resources development and knowledge management through training. This is corroborated by Kamalahmadi and Parast (2016)

Sustainability is understood as meeting environmental, economic and social guidelines, meeting present demand without compromising future demands Logistics capacity is understood as the timely adaptation of the activities of the logistics system to meet the different and seasonal demands along the chain. This is Definition of the elements associated with resilience in SCM

reinforced the idea that some systems are more responsive than others when considering the elements of resilience.

Still in the food sector, Burgos and Ivanov (2021) analysed retail's particularities, highlighting the pandemic's impact on the fluctuation of demand and consequently demanding greater responsiveness. The authors argue that shipping costs have increased due to the chaotic dynamics of inventory orders, leading to more frequent and erratic shipments. According to the authors, a positive point was the growth in demand and online sales channels that generate higher revenues. Another positive point of the food sector is highlighted by Hobbs (2021) which says the pandemic will likely accelerate the adoption of automation and digitisation in food supply chains.

Considering the transport sector, Narasimha et al. (2021) specifically analysed the impacts of the pandemic on maritime transport systems. They identified a considerable reduction in the quantity of maritime transport compared to the pre-pandemic period. In addition, the authors point out the need for a rapid response and improvements in resilience practices.

To enhance the resilience of the companies' supply chains, digital technologies can be cited. According to Hopkins (2021), to recover from COVID-19 impacts, companies need to invest in the process's digitisation and technologies; it is necessary to be innovative after an extreme disruption, according to Mora et al. (2021). Dutta et al. (2020) emphasise the 
MSCRA

4,1

6

importance of digital technologies to reduce impacts due to unexpected interruptions, minimising chain management risks.

Another example of how digital technologies may enhance resilience in the supply chain is mentioned by Gajek et al. (2020) when arguing that Artificial Intelligence impacts the analysis and decision-making resources along the chain, consequently increasing confidence in resilience aspects. Wang and Franke (2020) and Dutta et al. (2020) also point out the digital technologies to improve security in the supply chain. Belhadi et al. (2021) highlight the importance of Big Data Analytics (BDA) in SCM, providing real-time information on various activities; regarding the pandemic, authors mention that BDA helped overcome challenges posed by COVID-19.

The COVID-19 pandemic reaffirms the importance of resilience in companies of all sectors. Chowdhury et al. (2021) highlight that in this area, four major research themes have been frequent in the literature, namely, resilience strategies for management; impacts and recovery; the role of technology in the implementation of supply chain resilience; and sustainability strategies in light of the pandemic, which reinforces the importance of the theme presented in this study.

\section{Methodological procedures}

This research is characterised as being applied and with exploratory objectives, that is, to promote the expansion of debates in the analysed area. A mixed model was adopted as a research strategy, combining qualitative and quantitative approaches. The analysis of the survey parameters carried out follows a qualitative model. In contrast, the treatment of the data obtained follows a quantitative approach guided by the Fuzzy TOPSIS technique. For the development of this research, six well-defined stages were followed, as shown in Figure 1.

Stage 1 consisted of establishing the theoretical foundation for the development of the research. Bibliographic searches were carried out on the following scientific bases: Springer, Emerald insights, Science Direct, Taylor \& Francis and Scopus. The search terms used were: "Supply chain management", "COVID-19" and "resilience in the supply chain". Such terms were also used in a combined way through the "AND" function in searches.

Stage 2 consisted of developing the research instrument (questionnaire) used in the survey with academics experienced in the subject. The first part of the questionnaire was dedicated to the characterisation of respondents. The second part was to evaluate resilience elements in the SCM of Brazilian companies. The structuring of the second part of the questionnaire was based on the elements mentioned by Sawyerr and Harrison (2020), as shown in Table 1. The choice of this reference to base the questionnaire is due to the journal's relevance that published it in the field. It deals with specific aspects of resilience in the supply chain and was recently published in 2020 .

The items in the second part of the questionnaire were presented using affirmative phrases in the sense of being characterised as a critical point in the management of the supply chain of Brazilian companies (Table A1). Based on all their experience in the subject and the critical points evidenced by the COVID-19 pandemic, respondents evaluated each item and assigned one of the following alternatives: the reality described is not observed in the supply chains of Brazilian companies (A); the reality described is observed in the supply chains of few Brazilian companies, in a very punctual manner (B); the reality described is observed in the supply chains of a small but relevant percentage of Brazilian companies (C); and the reality described is observed in the supply chains of many Brazilian companies (D).

Stage 3 was characterised by the survey execution. It is worth mentioning that, before data collection, this study was approved by the university's research ethics committee. In Brazil, this approval is necessary for research involving human beings and their opinions. After the mentioned approval, 37 specialists were invited to answer the survey and 15 of them 


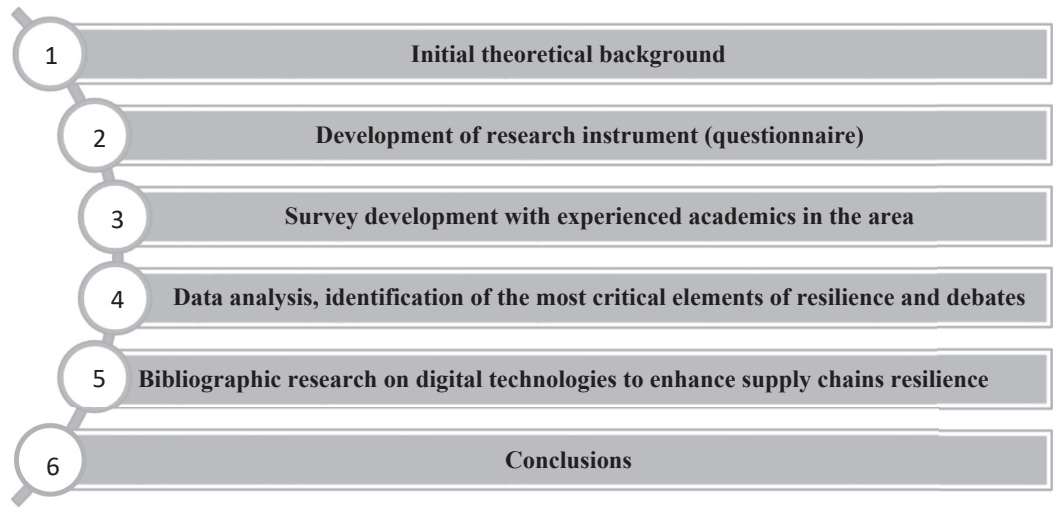

Source(s): Authors
Resilience in the supply chain

management

Figure 1.

Stages took to develop the research

accepted to participate, a return rate of $40.54 \%$. The minimum criteria for participation in the study were: to have a $\mathrm{PhD}$, participate in projects in supply chain management and have research published in specialised journals in the area considering the past five years. It is understood that with these characteristics, the quality of responses is increased. It is noteworthy that to follow the safety protocols proposed by the World Health Organization WHO in this pandemic period, the entire approach with respondents was made online using the platform of Google Forms and e-mails.

In Stage 4, data analysis and discussion of results were carried out. The first analysis performed corresponded to Cronbach's alpha to verify and guarantee the reliability of the research instrument, according to the recommendations of Christmann and Van Aelst (2006). A hierarchical cluster analysis was carried out in the sequence to identify how the research participants were grouped in terms of similarities. The justification for carrying out this analysis is that the application of Fuzzy TOPSIS allows for considerations and, therefore, to show how groups of respondents are formed in terms of their qualifications. The weightings adopted and their justifications will be presented in the results section.

For constructing the dendrogram in the hierarchical cluster analysis, information collected in the first part of the questionnaire and public information made available by the respondents on a scientific basis was used. To make the analysis possible, the information mentioned was coded as presented in Table 2.

Hierarchical cluster analysis was developed based on Arbolino et al. (2019) and Malhotra (2012) using the SPSS 24 software. The following parameters were used: hierarchical grouping, dendrogram, grouping method, Ward, Euclidean distance, standardisation of the $Z$-score, cluster analysis by cases and cut-off point to define the groups at a combined distance 5. Four groups were generated and details of each are presented in the results section.

Once the groups were identified, Fuzzy TOPSIS technique was used based on the guidelines proposed by Chen (2000) to order the items analysed according to the highest degree of observation in the respondents' perception. Thus, the first items in the ranking obtained correspond to the critical points observed in the supply chains of many Brazilian companies. Fuzzy TOPSIS, in particular, has the advantage of incorporating a certain degree of uncertainty in the measured responses, thus making the analysis more realistic. The fuzzification of the responses measured by the respondents used the information presented in Figure 2. 
MSCRA

4,1

8

Table 2.

Coding used to construct the dendrogram
It is also worth noting that the hierarchical cluster analysis showed four groups of respondents according to qualification. To consider uncertainties in this classification, it was decided to fuzzy the groups according to Figure 3.

With the fuzzy input data, the calculations were performed (based on the steps proposed by Chen (2000), adapted to the reality of our research). Table 3 presents these steps.

Then (Stage 5), a bibliographic search was carried out on a scientific basis to identify the contribution of digital technologies in enhancing resilience in supply chains. For this, the search terms "Digital technologies" and "Resilience in supply chain management" were combined. After debates were held in the light of the literature and the study's conclusions were established (Stage 6).

\section{Results and debates}

The presentation of results will follow the sequence described in the section on methodological procedures. Initially, Cronbach's alpha coefficient was calculated and the value obtained was 0.92 , indicating that the research instrument used has reliability.

\begin{tabular}{|c|c|c|c|c|}
\hline $\begin{array}{l}\text { Scientific articles } \\
\text { in the field }\end{array}$ & $\begin{array}{l}\text { Scholar } \\
\text { background }\end{array}$ & Time experience & $\begin{array}{l}\text { Human resources } \\
\text { training }\end{array}$ & $\begin{array}{l}\text { Laboratory coordination } \\
\text { in the area }\end{array}$ \\
\hline $\begin{array}{l}1=\text { up to } 10 \\
\text { articles }\end{array}$ & & \multirow{3}{*}{$\begin{array}{l}1=\text { up to } \\
10 \text { years } \\
2=\text { more than } \\
10 \text { years }\end{array}$} & \multirow{3}{*}{$\begin{array}{l}1=\text { is not a } \\
\text { doctoral advisor } \\
2=\text { is a doctoral } \\
\text { advisor }\end{array}$} & $1=$ does not coordinate \\
\hline $\begin{array}{l}2=\text { more than } 10 \\
\text { articles }\end{array}$ & $\begin{array}{l}2=\mathrm{PhD} \text { and } \\
\text { Post-doc }\end{array}$ & & & $2=$ Coordinate \\
\hline Source(s): Authors & & & & \\
\hline
\end{tabular}

Figure 2.

Fuzzification of the scale used in the survey

\begin{tabular}{|c|c|c|c|}
\hline Scale & \multicolumn{3}{|c|}{ Fuzzy Numbers } \\
\hline A & 0.00 & 0.00 & 0.33 \\
\hline B & 0.00 & 0.33 & 0.67 \\
\hline C & 0.33 & 0.67 & 1.00 \\
\hline D & 0.67 & 1.00 & 1.00 \\
\hline
\end{tabular}

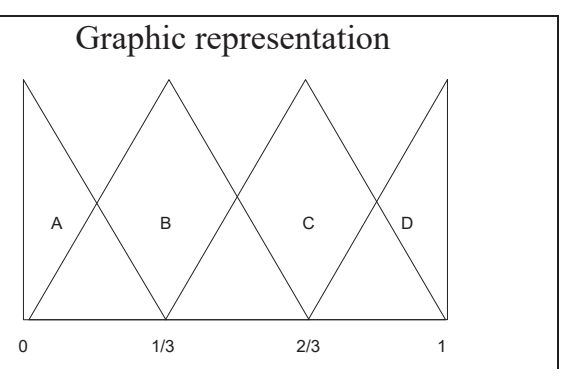

Source(s): Authors

\begin{tabular}{|c|c|c|c|}
\hline Group & \multicolumn{3}{|c|}{ Fuzzy Numbers } \\
\hline G1 & 0.00 & 0.00 & 0.33 \\
\hline G2 & 0.00 & 0.33 & 0.67 \\
\hline G3 & 0.33 & 0.67 & 1.00 \\
\hline G4 & 0.67 & 1.00 & 1.00 \\
\hline
\end{tabular}

Figure 3.

Fuzzification of the groups obtained

\section{Source(s): Authors}


P1 Structure the matrix that presents the fuzzified notes measured by the respondents (here called matrix G)

P2 Structure the vector that represents the level of qualification fuzzified for each of the identified groups (here called vector $\mathrm{E}$ )

P3 Normalisation of matrix G, thus obtaining matrix R (matrix 3)

P4 Obtaining matrix V (matrix 4), by multiplying the respondents' normalised fuzzy responses by the vector for the group in which the respondent was allocated

P5 Calculate the distance of each element of matrix $\mathrm{V}$ using equation 1 in relation to positive and negative ideas solutions

P6 Obtain the total distance of each alternative in relation to the positive and negative ideal solutions by adding the partial distances obtained in the previous phase according to equations 2 and 3

P7 Calculate each alternative's proximity coefficient (CCi) using equation 4 and order them according to values obtained
Resilience in the supply chain

management

$\widetilde{E}=\left[\widetilde{w}_{1}, \widetilde{w}_{2}, \ldots \widetilde{w}_{n}\right] ; \widetilde{w}_{j}=\left[w_{j 1}, w_{j 2}, w_{j 3}\right] ; \quad$ (Vector 2)

$\widetilde{R}=\left[\widetilde{r}_{i j}\right]_{m \times n}\left(\right.$ Matriz 2); $\widetilde{r}_{i j}=\left(\frac{a_{i j}}{C_{J}^{*}}, \frac{b_{i j}}{C_{J}^{*}}, \frac{c_{i j}}{C_{J}^{*}},\right) ; C_{J}^{*}=\max (\mathrm{i}) c_{i j}$

$\widetilde{V}=\left[\widetilde{v}_{i j}\right]_{m \times n}($ Matriz 3$) \rightarrow i=1,2, . . m ; j=1,2, . . n ; \widetilde{v}_{i j}=\widetilde{r}_{i j}(.) \widetilde{w}_{i j}$

$d(\widetilde{m}, \tilde{n})=\sqrt{\frac{1}{3}\left[\left(m_{1}-n_{1}\right)^{2}+\left(m_{2}-n_{2}\right)^{2}+\left(m_{3}-n_{3}\right)^{2}\right]}$

(Equação 1)

$A^{*}=\left[\widetilde{v}_{1}^{*}, \widetilde{v}_{2}^{*}, \widetilde{v}_{3}^{*}\right]$ where, $\widetilde{v}_{j}^{*}=[1,1,1] \rightarrow$ positive ideal solution

$A^{-}=\left[\widetilde{v}_{1}^{-}, \widetilde{v}_{2}^{-}, \widetilde{v}_{3}^{-}\right]$where, $\widetilde{v}_{j}^{*}=[0,0,0] \rightarrow$ negative ideal solution

$d_{i}^{*}=\sum_{j=1}^{n} d\left(\widetilde{v}_{i j}, \widetilde{v}_{j}^{*}\right) \rightarrow$ total distance to the positive solution

(equation 2)

$d_{i}^{-}=\sum_{j=1}^{n} d\left(\widetilde{v}_{i j}, \widetilde{v}_{j}^{-}\right) \rightarrow$ total distance to the negative solution

(equation 3)

$C C_{i}=\frac{d_{i}^{-}}{\left(d_{i}^{*}+d_{i}^{-}\right)} \rightarrow$ proximity coefficient (equation 4$)$
Table 3.

Steps performed on Fuzzy TOPSIS

Then, the hierarchical cluster analysis was carried out to group the respondents according to similarities. Using information collected in the first part of the questionnaire, public information provided by the respondents, and the coding described in Tables 2 and 4 was structured and used to construct the dendrogram shown in Figure 4.

Through the dendrogram obtained (Figure 4), it was possible to identify four groups. Group 4 is composed of respondents who are in the maximum ranges of the analysed criteria, that is, most of the respondents received coding 2 in almost all aspects. Thus, it is understood that this group stands out in terms of qualifications and greater weighting will be given to respondents in the Fuzzy TOPSIS calculations. The second most relevant group was Group 3 since most respondents were allocated to the maximum ranges of at least three of the five analysed criteria. Group 2 is presented, which despite most of the respondents being allocated in the initial ranges (codification 1 ) of the aspects considered, some " 2 " codifications are still observed for some aspects. Finally, Group 1 is composed of the respondents with the lowest experience. Based on the dendrogram results, weights were discussed and the weighting indices are presented in Figure 3.

With the defined groupings and fuzzified responses, you can start calculating the Fuzzy TOPSIS. The score obtained by each of the 15 participants were replaced by the corresponding fuzzy designation presented in the methodological procedures section. For 
MSCRA

4,1

\begin{tabular}{llccccc}
\hline & & $\begin{array}{c}\text { Scientific } \\
\text { articles in the } \\
\text { field }\end{array}$ & $\begin{array}{c}\text { Scholar } \\
\text { background }\end{array}$ & $\begin{array}{c}\text { Time } \\
\text { experience }\end{array}$ & $\begin{array}{c}\text { Human } \\
\text { resources } \\
\text { training }\end{array}$ & $\begin{array}{c}\text { Laboratory } \\
\text { coordination }\end{array}$ \\
\hline G1 & R10 & 1 & 1 & 1 & 1 & 1 \\
G1 & R11 & 1 & 1 & 1 & 1 & 1 \\
G1 & R14 & 1 & 1 & 1 & 1 & 1 \\
G2 & R1 & 1 & 2 & 2 & 1 & 1 \\
G2 & R7 & 1 & 1 & 2 & 1 & 1 \\
G2 & R12 & 1 & 1 & 2 & 1 & 1 \\
G2 & R13 & 1 & 1 & 2 & 1 & 2 \\
G3 & R3 & 2 & 1 & 2 & 1 & 1 \\
G3 & R15 & 2 & 1 & 2 & 2 & 2 \\
G3 & R2 & 2 & 1 & 2 & 1 & 1 \\
G3 & R8 & 2 & 1 & 2 & 2 & 1 \\
G4 & R4 & 2 & 2 & 2 & 2 & \\
G4 & R9 & 2 & 2 & 2 & 2 & 2 \\
G4 & R5 & 2 & 2 & 2 & 2 & \\
G4 & R6 & 2 & 2 & 2 & 2 & \\
Source(s): Authors & & & & & \\
\end{tabular}

Table 4.

Qualifications of coded respondents

$\underline{10}$

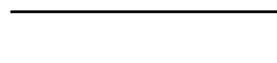

Figure 4.

Dendrogram showing groupings of respondents according to similarities

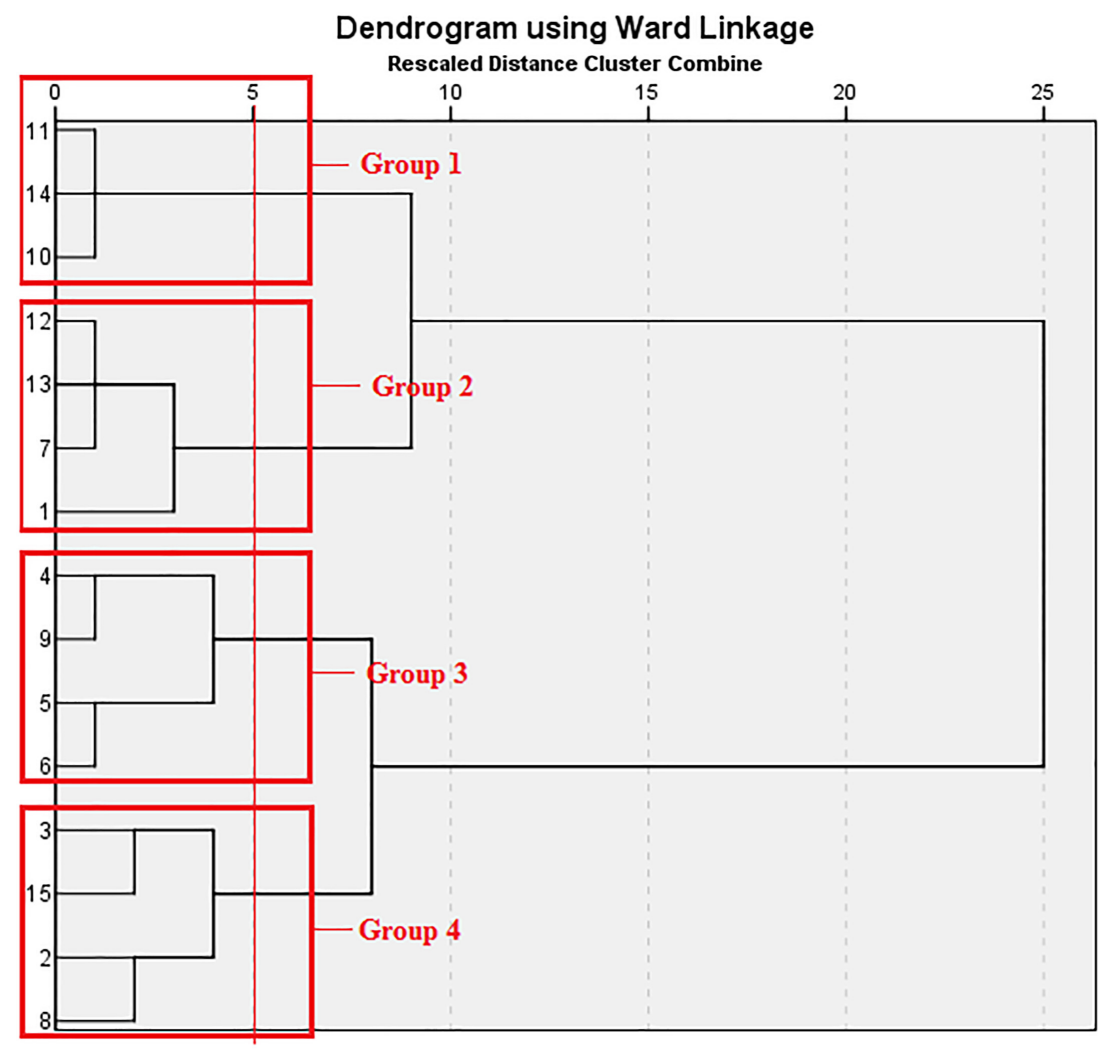

Source(s): Authors 
reasons of size, the matrix including fuzzy notes is not shown here. This matrix was fuzzyficated and normalised, being in the sequence multiplied by the fuzzified weights of each group, thus obtaining matrix V. Again, it was not possible to present it here due to the size of the resulting matrix.

Using Equation 1 and the values presented in matrix V, the distances of each element about the ideal positive and negative solutions were calculated, the same being shown in Tables 5 and 6 . The total distances of each element about each ideal solution were obtained by adding the distances and are also presented in Tables 5 and 6 .

With the di* and di-values for each element and using equation 4 , the proximity coefficient (CCi) was calculated, as shown in Table 7. Finally, these coefficients were used to order comparatively the supply chain resilience elements analysed (Table 8).

Analysing the obtained results, it is possible to observe that three elements of resilience evidenced by the pandemic of COVID-19 are highlighted as the most critical when analysed comparatively. These elements are related to aspects of decision-making, human resources and security. Decision-making is a daily and fundamental element in managing supply chains (Sawyerr and Harrison, 2020; Singh et al., 2019). As a result, managers must pay special attention to achieving greater resilience in SCM. Another essential point evidenced by the pandemic is the need to develop human resources that operate throughout the supply chain, considering both direct and indirect employees (Kamalahmadi and Parast, 2016). In the third position, it is possible to note security issues; as Ivanov (2020) highlighted, it becomes essential in defining strategies and supporting more assertive decisions.

Analysing the ranking obtained and academic literature, it is possible to note how digital technologies may enhance SCM resilience. For the first item in the ranking, Fossa Wamba et al. (2018) argue that decision-making effectiveness in supply chains depends on the data availability. In this way, technologies as IoT and Bigdata can provide different kinds of data. Regarding human resources development, Kamalahmadi and Parast (2016), Hosseini and Ivanov (2019) and Samson (2020) recommend the alignment among recruitment process, managerial skills development and technological digital to become management more resilient. Finally, regarding security aspects, digital technologies can substantially improve resilience through dynamic data storage, processing capacity, transparency, data protection and reliability (Dutta et al., 2020; Ivanov, 2020).

\section{Conclusions}

This article aimed to identify the elements of resilience presented by Sawyerr and Harrison (2020), which are comparatively more critical in managing the supply chain of Brazilian companies. In addition, we also debated possible digital technologies mentioned by literature to enhance them. Given the exposure in Section 4, it can be said that the main objective was achieved.

Comparatively, the three most critical elements of resilience are decision-making, human resources and security. More in-depth studies need to be conducted to define the correct level of criticality of each element. However, we believe that the ordering presented here allows a better direction of debates on the subject and future research. According to the reference debates, it is possible to perceive the importance of digital technologies in enhancing the elements of resilience in supply chains.

This study has implications for theory and practice. For theory, it is understood that researchers in future studies can use the findings presented here since experts in the field presented consolidated information, and appropriate methods are used for data analysis, that is, from the results achieved new research aimed at expanding debates in the area of resilience in supply chains and the impact of digital technologies in this context can be developed. Regarding the implications for practice, managers involved in the supply chain can use the
Resilience in the supply chain

management 
MSCRA

4,1

12
고

괴

게 괴

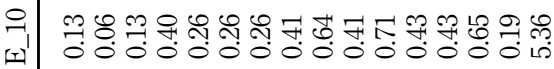

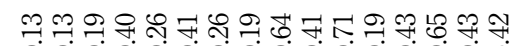

000000000000000 L

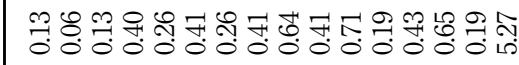

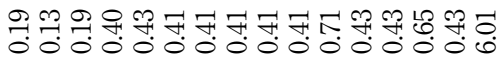
(2)

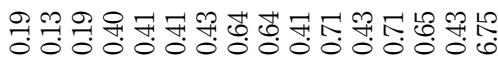

닝

니

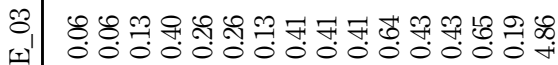

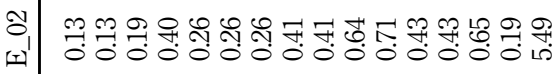

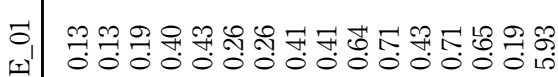

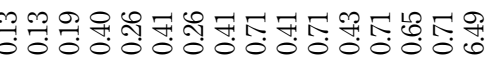

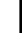

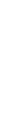

Table 5.

Distances to the ideal positive solution and total distance $\left(\mathrm{di}^{*}\right)$ 
Resilience in the supply chain management

13
Table 6. Distances to the ideal negative solution and total distance (di-) 
MSCRA

4,1

14

information presented here to critically analyse the resilience of their organisations and make decisions that support the company's strategic planning, debating the importance of implementing digital technologies in the management of supply chains.

The study carried out is exploratory and its limitations should be mentioned. The main limitation is the sample size, as 15 researchers participated; however, the qualification of participants with good knowledge and experience in the subject stands out. As future works, the following stand out: (1) carrying out specific studies on the four elements that are comparatively more critical; (2) application of the study with professionals from other regions to validate the results considering other management contexts; and (3) develop and validate an action plan that aims to enhance the critical elements of resilience in supply chains.

\begin{tabular}{lccclccc}
\hline$\#$ & d- & d* & CCi & $\#$ & d- & d* & CCi \\
\hline E_01 & 11.30 & 5.93 & 0.3442 & E_08 & 11.71 & 5.42 & 0.3163 \\
E_02 & 11.65 & 5.49 & 0.3204 & E_09 & 11.31 & 6.01 & 0.3471 \\
E_03 & 12.10 & 4.86 & 0.2866 & E_10 & 11.71 & 5.36 & 0.3141 \\
E_04 & 11.35 & 5.93 & 0.3432 & E_11 & 10.59 & 6.77 & 0.3900 \\
E_05 & 10.37 & 7.13 & 0.4075 & E_12 & 11.38 & 5.77 & 0.3365 \\
E_06 & 10.78 & 6.75 & 0.3850 & E_13 & 10.80 & 6.49 & 0.3753 \\
E_07 & 11.81 & 5.27 & 0.3083 & & & & \\
\multicolumn{2}{l}{ Source(s): Authors } & & & & & & \\
\end{tabular}

Table 7.

Proximity coefficient (CCi)

Source(s): Authors

Table 8.

Ordering of the analysed resilience elements

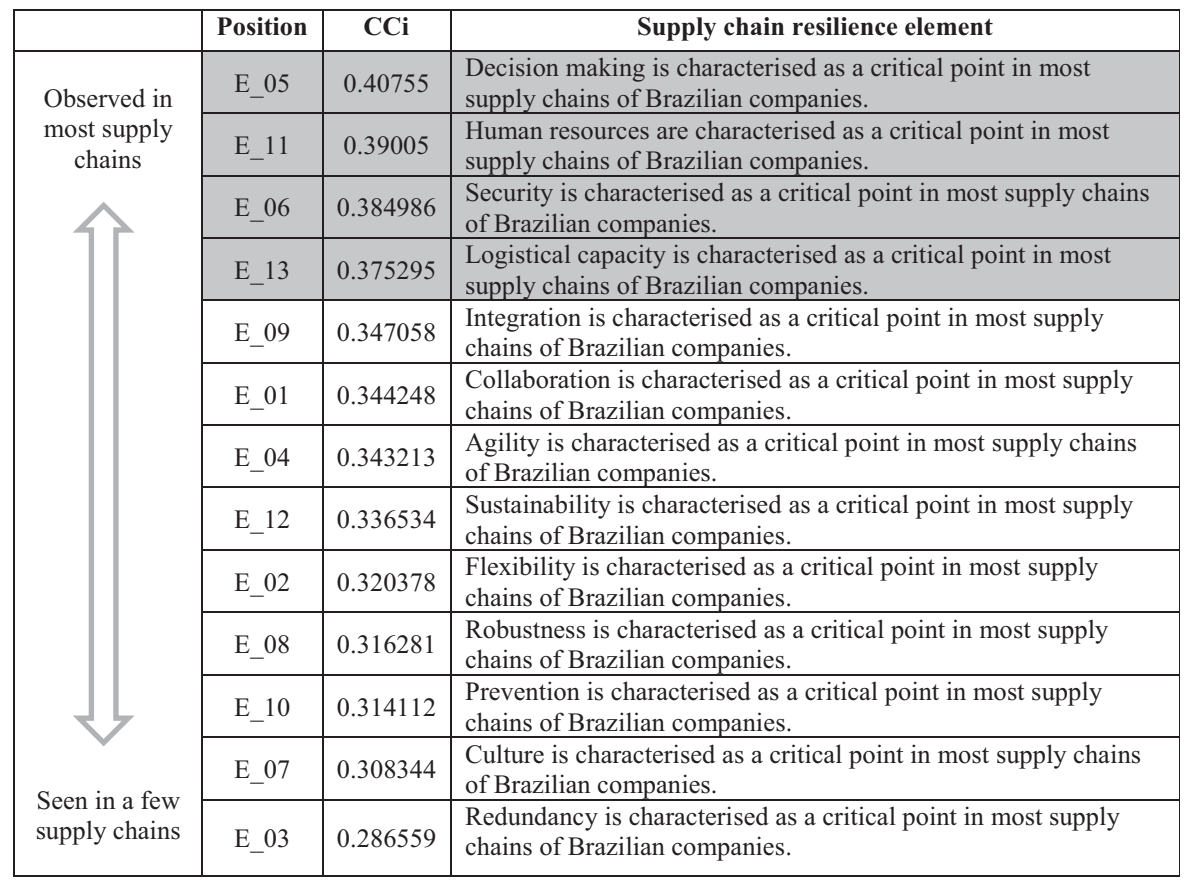

Source(s): Authors 


\section{References}

Adobor, H. (2019), "Supply chain resilience: a multi-level framework", International Journal of Logistics Research and Applications, Taylor \& Francis, Vol. 22 No. 6, pp. 533-556.

Alfarsi, F., Lemke, F. and Yang, Y. (2019), "The importance of supply chain resilience: an empirical investigation”, Procedia Manufacturing, Elsevier B.V., Vol. 39, pp. 1525-1529.

Ali, M., Rahman, S.M. and Frederico, G.F. (2021), "Capability components of supply chain resilience for readymade garments (RMG) sector in Bangladesh during COVID-19", Modern Supply Chain Research and Applications, Vol. 3 No. 2, pp. 127-144, doi: 10.1108/MSCRA-06-2020-0015.

Aloini, D., Dulmin, R., Mininno, V. and Ponticelli, S. (2015), "Key antecedents and practices for supply chain management adoption in project contexts", International Journal of Project Management, Elsevier and IPMA, Vol. 33 No. 6, pp. 1301-1316.

Anholon, R., Rampasso, I.S., Martins, V.W.B., Serafim, M.P., Leal Filho, W. and Quelhas, O.L.G. (2021), "COVID-19 and the targets of SDG 8: reflections on Brazilian scenario", Kybernetes, Vol. 50 No. 5, pp. 1679-1686, doi: 10.1108/K-12-2020-0833.

Arbolino, R., Boffardi, R. and Ioppolo, G. (2019), "The effectiveness of European energy policy on the Italian system: regional evidences from a hierarchical cluster analysis approach", Energy Policy, Elsevier, Vol. 132 No. December 2018, pp. 47-61.

Ballou, R.H. (2004), Business Logistics/Supply Chain Management: Planning, Organising and Controlling the Supply Chain, 5th ed., Pearson/Prentice Hall, New Jersey, NJ.

Belhadi, A., Kamble, S., Jabbour, C.J.C., Gunasekaran, A., Ndubisi, N.O. and Venkatesh, M. (2021), "Manufacturing and service supply chain resilience to the COVID-19 outbreak: lessons learned from the automobile and airline industries", Technological Forecasting and Social Change, Elsevier, Vol. 163 November 2020, p. 120447.

Burgos, D. and Ivanov, D. (2021), "Food retail supply chain resilience and the COVID-19 pandemic: a digital twin-based impact analysis and improvement directions", Transportation Research Part E: Logistics and Transportation Review, Elsevier, Vol. 152 March, p. 102412.

Cai, M. and Luo, J. (2020), "Influence of COVID-19 on manufacturing industry and corresponding countermeasures from supply chain perspective", Journal of Shanghai Jiaotong University (Science), Vol. 25 No. 4, pp. 409-416.

Cao, M., Vonderembse, M.A. and Zhang, Q. (2010), "Supply chain collaboration : conceptualisation and instrument development", International Journal of Production Research May 2013, pp. 37-41.

Chen, C.T. (2000), "Extensions of the TOPSIS for group decision-making under fuzzy environment", Fuzzy Sets and Systems, Vol. 114 No. 1, pp. 1-9.

Cheng, J.H. and Lu, K.L. (2017), "Enhancing effects of supply chain resilience: insights from trajectory and resource-based perspectives”, Supply Chain Management, Vol. 22 No. 4, pp. 329-340.

Chowdhury, M.T., Sarkar, A., Saha, P.K. and Anik, R.H. (2020), "Enhancing supply resilience in the COVID-19 pandemic: a case study on beauty and personal care retailers", Modern Supply Chain Research and Applications, Vol. 2 No. 3, pp. 143-159.

Chowdhury, P., Paul, S.K., Kaisar, S. and Moktadir, M.A. (2021), "COVID-19 pandemic related supply chain studies: a systematic review”, Transportation Research Part E: Logistics and Transportation Review, Elsevier, Vol. 148 August 2020, p. 102271.

Christmann, A. and Van Aelst, S. (2006), "Robust estimation of Cronbach's alpha", Journal of Multivariate Analysis, Vol. 97 No. 7, pp. 1660-1674.

Coopmans, I., Bijttebier, J., Marchand, F., Mathijs, E., Messely, L., Rogge, E., Sanders, A. and Wauters, E. (2021), "COVID-19 impacts on Flemish food supply chains and lessons for agri-food system resilience”, Agricultural Systems, Elsevier, Vol. 190 November 2020, 103136, ISSN 0308-521X, doi: 10.1016/j.agsy.2021.103136.

Dutta, P., Choi, T.M., Somani, S. and Butala, R. (2020), "Blockchain technology in supply chain operations: applications, challenges and research opportunities", Transportation Research Part E: Logistics and Transportation Review, Elsevier, Vol. 142 August, p. 102067.

Resilience in the supply chain

management 
MSCRA

4,1

16

Dwivedi, S.K., Amin, R. and Vollala, S. (2020), "Blockchain based secured information sharing protocol in supply chain management system with key distribution mechanism", Journal of Information Security and Applications, Elsevier, Vol. 54, doi: 10.1016/j.jisa.2020.102554.

Elibal, K. and Özceylan, E. (2021), "A systematic literature review for industry 4.0 maturity modeling: state-of-the-art and future challenges”, Kybernetes, Vol. 50 No. 11, pp. 2957-2994, doi: 10.1108/K07-2020-0472.

Fosso Wamba, S., Gunasekaran, A., Dubey, R. and Ngai, E.W.T. (2018), "Big data analytics in operations and supply chain management", Annals of Operations Research, Springer US, Vol. 270 Nos 1-2, pp. 1-4.

Gajek, S., Lees, M. and Jansen, C. (2020), "IIoT and cyber-resilience: could blockchain have thwarted the Stuxnet attack?", AI and Society, Springer London, No. 0123456789, doi: 10.1007/s00146-02001023-w.

Green, K.W., Inman, R.A., Sower, V.E. and Zelbst, P.J. (2019), "Comprehensive supply chain management model", Supply Chain Management, Vol. 24 No. 5, pp. 590-603.

Hobbs, J.E. (2021), "The Covid-19 pandemic and meat supply chains", Meat Science, Elsevier, No. January, p. 108459.

Hopkins, J.L. (2021), “An investigation into emerging industry 4.0 technologies as drivers of supply chain innovation in Australia", Computers in Industry, Elsevier B.V., Vol. 125, p. 103323.

Hosseini, S. and Ivanov, D. (2019), "A new resilience measure for supply networks with the ripple effect considerations: a Bayesian network approach", Annals of Operations Research, Springer US. doi: 10.1007/s10479-019-03350-8.

Hosseini, S., Ivanov, D. and Dolgui, A. (2019), "Review of quantitative methods for supply chain resilience analysis", Transportation Research Part E, Elsevier, Vol. 125 No. March, pp. 285-307.

Ivanov, D. (2020), "Viable supply chain model: integrating agility, resilience and sustainability perspectives-lessons from and thinking beyond the COVID-19 pandemic", Annals of Operations Research, Springer US. doi: 10.1007/s10479-020-03640-6.

Jabbour, A.B.L.D.S., Jabbour, C.J.C., Hingley, M., Vilalta-Perdomo, E.L., Ramsden, G. and Twigg, D. (2020), "Sustainability of supply chains in the wake of the coronavirus (COVID-19/SARS-CoV-2) pandemic: lessons and trends", Modern Supply Chain Research and Applications, Vol. 2 No. 3, pp. 117-122.

Kamalahmadi, M. and Parast, M.M. (2016), "A review of the literature on the principles of enterprise and supply chain resilience: major findings and directions for future research", International Journal of Production Economics, Elsevier, Vol. 171, pp. 116-133.

Karmaker, C.L. and Ahmed, T. (2020), "Modeling performance indicators of resilient pharmaceutical supply chain”, Modern Supply Chain Research and Applications, Vol. 2 No. 3, pp. 179-205.

Love, D.C., Allison, E.H., Asche, F., Belton, B., Cottrell, R.S., Froehlich, H.E., Gephart, J.A., Hicks, C.C., Little, D.C., Nussbaumer, E.M., da Silva, P.P., Poulain, F., Rubio, A., Stoll, J.S., Tlusty, M.F., Thorne-Lyman, A.L., Troell, M. and Zhang, W. (2021), "Emerging COVID-19 impacts, responses, and lessons for building resilience in the seafood system", Global Food Security, Elsevier B.V., Vol. 28, 100494, ISSN 2211-9124, doi: 10.1016/j.gfs.2021.100494.

Malhotra, N.K. (2012), Pesquisa de Marketing, Bookman, Porto Alegre, RS, Brasil.

Modak, N.M., Sinha, S., Raj, A., Panda, S., Merigó, J.M. and Lopes de Sousa Jabbour, A.B. (2020), "Corporate social responsibility and supply chain management: framing and pushing forward the debate", Journal of Cleaner Production, Vol. 273, doi: 10.1016/j.jclepro.2020.122981.

Mora, H., Morales-Morales, M.R., Pujol-López, F.A. and Mollá-Sirvent, R. (2021), "Social cryptocurrencies as model for enhancing sustainable development", Kybernetes, Vol. 50 No. 10, pp. 2883-2916, doi: 10.1108/K-05-2020-0259.

Narasimha, P.T., Jena, P.R. and Majhi, R. (2021), "Impact of COVID-19 on the Indian seaport transportation and maritime supply chain”, Transport Policy, Elsevier, Vol. 110 No. May, pp. 191-203. 
Paul, S.K. and Chowdhury, P. (2021), "A production recovery plan in manufacturing supply chains for a high-demand item during COVID-19", International Journal of Physical Distribution and Logistics Management, Vol. 51 No. 2, pp. 104-125, doi: 10.1108/IJPDLM-04-2020-0127.

Queiroz, M.M., Ivanov, D., Dolgui, A. and Fosso Wamba, S. (2020), "Impacts of epidemic outbreaks on supply chains: mapping a research agenda amid the COVID-19 pandemic through a structured literature review", Annals of Operations Research, Springer US. doi: 10.1007/ s10479-020-03685-7.

Samson, D. (2020), "Operations/supply chain management in a new world context", Operations Management Research, Operations Management Research, Vol. 13 Nos 1-2, pp. 1-3.

Sawyerr, E. and Harrison, C. (2020), "Developing resilient supply chains: lessons from high-reliability organisations”, Supply Chain Management, Vol. 25 No. 1, pp. 77-100.

Scholten, K. and Schilder, S. (2015), "The role of collaboration in supply chain resilience", Supply Chain Management: An International Journal, No. November 2014, doi: 10.1108/SCM-11-2014-0386.

Sharma, S. and Modgil, S. (2019), "TQM, SCM and operational performance: an empirical study of Indian pharmaceutical industry", Business Process Management Journal, Vol. 26 No. 1, pp. 331-370.

Sharma, A., Adhikary, A. and Borah, S.B. (2020), "Covid-19's impact on supply chain decisions: strategic insights from NASDAQ 100 firms using Twitter data”, Journal of Business Research, Elsevier, Vol. 117 May, pp. 443-449.

Singh, R.K., Koul, S. and Kumar, P. (2017), "Analysing the interaction of factors for flexibility in supply chains", Journal of Modelling in Management, Vol. 12 No. 4, pp. 671-689.

Singh, S., Kumar, R., Panchal, R. and Tiwari, M.K. (2021), "Impact of COVID-19 on logistics systems and disruptions in food supply chain", International Journal of Production Research, Vol. 59 No. 7, pp. 1993-2008, doi: 10.1080/00207543.2020.1792000.

Theagaraja, S.S. and Manohar, H.L. (2015), "Lean management practices to improve supply chain performance of leather footwear industry", 2015 International Conference on Industrial Engineering and Operations Management (IEOM), pp. 1-5.

Tortorella, G.L., Miorando, R. and Marodin, G. (2017), "Lean supply chain management: empirical research on practices, contexts and performance", International Journal of Production Economics, Vol. 193 July, pp. 98-112.

Tukamuhabwa, B.R., Stevenson, M., Busby, J. and Zorzini, M. (2015), "Supply chain resilience: definition, review and theoretical foundations for further study", International Journal of Production Research, Taylor \& Francis, Vol. 53 No. 18, pp. 5592-5623.

Walker-Munro, B. (2021), "A case for the use of cyber-systemics to combat financial crime in Australia”, Kybernetes, Vol. 50 No. 11, pp. 3082-3105, doi: 10.1108/k-09-2020-0581.

Wang, S.S. and Franke, U. (2020), "Enterprise IT service downtime cost and risk transfer in a supply chain", Operations Management Research, Vol. 13 Nos 1-2, pp. 94-108.

Yadav, S., Luthra, S. and Garg, D. (2020), "Internet of things (IoT) based coordination system in Agrifood supply chain: development of an efficient framework using DEMATEL-ISM", Operations Management Research. doi: 10.1007/s12063-020-00164-x.

Yaya, S., Yaya, S., Otu, A., Otu, A. and Labonté, R. (2020), "Globalisation in the time of COVID-19: repositioning Africa to meet the immediate and remote challenges", Globalization and Health, Vol. 16 No. 1, pp. 1-7.

Yu, D.E.C., Razon, L.F. and Tan, R.R. (2020), "Can global pharmaceutical supply chains scale up sustainably for the COVID-19 crisis?”, Resources, Conservation and Recycling, Elsevier, Vol. 159 April, p. 104868.
Resilience in the supply chain

management 


\section{MSCRA \\ Appendix}

\section{4,1}

\# Questionnaire item

18

1 Collaboration is characterised as a critical point in most supply chains of Brazilian companies.

(Collaboration is understood as the integration of elements and the mutual availability of resources among agents in the supply chain to optimise the chain's management as a whole)

2 Flexibility is characterised as a critical point in most supply chains of Brazilian companies. (Flexibility is understood as the availability of various transportation options, products, processes, order fulfilment and even contracts with suppliers)

3 Redundancy is characterised as a critical point in most supply chains of Brazilian companies.

(Redundancy is understood as the existence of alternative plans in terms of capacity, employees, facilities and even the number of suppliers)

4 Agility is characterised as a critical point in most supply chains of Brazilian companies. (Agility is understood as the ability of the chain to respond and adapt to meet unforeseen demands)

5 Decision-making is characterised as a critical point in most supply chains of Brazilian companies.

(Decision-making is understood as the definition from the layout of the chain's operations network to the choice of warehouse locations, distribution centres and manufacturing facilities)

6 Security is characterised as a critical point in most supply chains of Brazilian companies. (Security is understood as issues related to information technology for data security)

7 Culture is characterised as a critical point in most supply chains of Brazilian companies. (Culture is understood to be the form that generates learning along the chain, as well as the sharing and recording of information and risk forecasting)

8 Robustness is characterised as a critical point in most supply chains of Brazilian companies. (Robustness is understood as the supply chain's capacity to transform, learn and innovate)

9 Integration is characterised as a critical point in most supply chains of Brazilian companies. Integration is understood as to how supply chain agents and suppliers guarantee competitive advantage

10 Prevention is characterised as a critical point in most supply chains of Brazilian companies. (Prevention is understood as the ability to predict the risks inherent in the operation of the supply chain)

11 Human resources are characterised as a critical point in most supply chains of Brazilian companies (Human resources are understood as management for the development of human resources and knowledge management through training)

12 Sustainability is characterised as a critical point in most supply chains of Brazilian companies. (Sustainability is understood as meeting environmental, economic and social guidelines, meeting present demand without compromising future demands)

13 Logistical capacity is characterised as a critical point in most supply chains of Brazilian companies

Table A1.

Items that made up the questionnaire
(Logistics capacity is understood as the timely adaptation of the activities of the logistics system to meet the different and seasonal demands along the chain)

Source(s): Adapted de Sawyerr and Harrison (2020)

\section{Corresponding author}

Vitor William Batista Martins can be contacted at: vitor.martins@uepa.br

For instructions on how to order reprints of this article, please visit our website: 